\title{
Anionic Extraction for Efficient Recovery of Biobased 2,3-Butanediol-A Platform for Bulk and Fine Chemicals
}

Drabo, Peter; Tiso, Till; Heyman, Benedikt; Sarikaya, Eda; Gaspar, Paula; Förster, Jochen; Büchs, Jochen; Blank, Lars Mathias; Delidovich, Irina

\author{
Published in: \\ ChemSusChem (Print) \\ Link to article, DOI: \\ $10.1002 /$ cssc.201700899 \\ Publication date: \\ 2017 \\ Document Version \\ Peer reviewed version \\ Link back to DTU Orbit
}

Citation (APA):

Drabo, P., Tiso, T., Heyman, B., Sarikaya, E., Gaspar, P., Förster, J., Büchs, J., Blank, L. M., \& Delidovich, I. (2017). Anionic Extraction for Efficient Recovery of Biobased 2,3-Butanediol-A Platform for Bulk and Fine Chemicals. ChemSusChem (Print), 10(16), 3252-3259. https://doi.org/10.1002/cssc.201700899

\section{General rights}

Copyright and moral rights for the publications made accessible in the public portal are retained by the authors and/or other copyright owners and it is a condition of accessing publications that users recognise and abide by the legal requirements associated with these rights.

- Users may download and print one copy of any publication from the public portal for the purpose of private study or research.

- You may not further distribute the material or use it for any profit-making activity or commercial gain

- You may freely distribute the URL identifying the publication in the public portal 


\title{
Anionic Extraction for Efficient Recovery of Biobased 2,3-Butanediol-A Platform for Bulk and Fine Chemicals
}

\author{
Peter Drabo, ${ }^{[\mathrm{a}]}$ Till Tiso, $^{[\mathrm{b}]}$ Benedikt Heyman, ${ }^{[\mathrm{c}]}$ Eda Sarikaya, ${ }^{[\mathrm{b}]}$ Paula Gaspar, ${ }^{[\mathrm{d}]}$ \\ Jochen Förster, ${ }^{[\mathrm{d}]}$ Jochen Büchs, ${ }^{[\mathrm{c}]}$ Lars Mathias Blank, $^{[\mathrm{b}]}$ and Irina Delidovich ${ }^{[\mathrm{a}]}$
}

2,3-Butanediol (BDO) presents a promising platform molecule for the synthesis of basic and fine chemicals. Biotechnological production of BDO from renewable resources with living microbes enables high concentrations in the fermentation broth. The recovery of high-boiling BDO from an aqueous fermentation broth presents a subsequent challenge. A method is proposed for BDO isolation based on reversible complexation with phenylboronate in an anionic complex. BDO can be recovered by back-extraction into an acidic solution. The composition of the extracted species was determined by NMR spectroscopy MS, and GC-MS methods. The conditions of extraction and back-extraction were optimized by using commercial BDO and finally applied to different fermentation broths. Up to 72-93\% BDO can be extracted and up to $80-90 \%$ can be back-extracted under the optimized conditions. Purified bio-BDO was used in the presence of sulfuric acid for the synthesis of methyl ethyl ketone, an established organic solvent and discussed tailor-made biofuel.

\section{Introduction}

Biotechnologically manufactured 2,3-butanediol (BDO) was indicated as a promising platform chemical as long ago as the 1940s. ${ }^{[1]}$ Production of BDO was scaled up to pilot-plant volume by considering the diol as an intermediate for synthesis of 1,3-butadiene. Rapid development of refinery processes in the 1950s resulted in shutting down of biobased production of BDO owing to the availability of inexpensive fossil feedstocks. ${ }^{[1 a]}$ Later, with the aim of developing sustainable technologies, fermentative processes were revisited. Recent achievements in synthetic biology have enabled greatly improved efficiency of fermentation processes with the titer of BDO as high as $150 \mathrm{~g} \mathrm{~L}^{-1}$. $^{[2]}$ Enzymatic synthesis of BDO has already been industrialized. ${ }^{[3]}$

[a] P. Drabo, Dr. I. Delidovich

Chair of Heterogeneous Catalysis and Chemical Technology

RWTH Aachen University, Worringerweg 2

52074 Aachen (Germany)

E-mail: delidovich@itmc.rwth-aachen.de

[b] Dr. T. Tiso, E. Sarikaya, Prof. Dr. L. M. Blank iAMB-Institute of Applied Microbiology

ABBt-Aachen Biology and Biotechnology RWTH Aachen University, Worringerweg 1 52074 Aachen (Germany)

[c] B. Heyman, Prof. Dr. J. Büchs

Chair of Biochemical Engineering, Aachener Verfahrenstechnik RWTH Aachen University, Fockenbeckstrasse 51 52074 Aachen (Germany)

[d] Dr. P. Gaspar, Prof. Dr. J. Förster

The Novo Nordisk Foundation Center for Biosustainability Technical University of Denmark, Kemitorvet, Building 220 DK-2800, Kgs. Lyngby (Denmark)

$\square$ Supporting Information and the ORCID identification number(s) for the iD author(s) of this article can be found under https://doi.org/10.1002/ cssc. 201700899.
Along with the abovementioned utilization of BDO for the production of 1,3-butadiene, the diol can be applied to the production of other value-added chemicals. BDO can be converted into methyl ethyl ketone (MEK), ${ }^{[4]}$ which is currently used as a solvent, but can also be utilized as a fuel additive owing to its high heat capacity of $33.7 \mathrm{MJ} \mathrm{kg}^{-1}$. ${ }^{[5]}$ Moreover, BDO itself exhibits a high heat capacity of $27.2 \mathrm{MJ} \mathrm{kg}^{-1}$ and can be considered as a fuel blend. ${ }^{[6]}$ Alternatively, BDO can be converted into a dioxolane mixture, which can be potentially used as a gasoline blending component, diesel oxygenate, and industrial solvent. ${ }^{[7]} \mathrm{BDO}$ is a valuable substrate for fine chemicals, for example, diacetyl applied as a flavoring agent in the food industry. ${ }^{[8]}$ Due to the presence of two stereocenters, three stereoisomers of $\mathrm{BDO}$ are known, namely, $(2 R, 3 R)-\mathrm{BDO}$, $(2 \mathrm{~S}, 3 \mathrm{~S})-\mathrm{BDO}$, and the meso-form (2S,3R)-BDO (Figure $1 \mathrm{~S}$ in the Supporting Information). Stereoselective production of BDO is of great interest, owing to its applicability in asymmetric synthesis with chiral auxiliaries possessing $C_{2}$ symmetry. ${ }^{[9]}$ Nowadays, BDO is manufactured based on 2-butene, which is available as a component of crack gases. Chlorohydrination of 2,3butene results in a mixture of cis- and trans-2,3-butene oxides. The hydrolysis of this mixture gives rise to a commercial product composed of about $80 \%$ meso- and $20 \%$ rac-BDO. ${ }^{[10]}$ Regarding the stereoselectivity of BDO production, synthetic biology excels the refinery because tailoring of a microbial strain allows the production of the desired stereoisomer of biobased BDO. ${ }^{[11]}$

The recovery of $\mathrm{BDO}$ from a fermentation broth still remains a tedious step in the BDO manufacturing process. ${ }^{[11]} \mathrm{A}$ fermentation broth presents a complex mixture of organic substances and inorganic salts dissolved in water. The high boiling point of BDO of about $180^{\circ} \mathrm{C}$ hampers its distillation from the solution: recovery first requires evaporation of water and all other 
components with lower boiling points. Other conventional separation methods, such as pervaporation, ${ }^{[12]}$ steam stripping, ${ }^{[6]}$ and reverse osmosis, ${ }^{[11 c]}$ appeared to be energy intensive as well. Vacuum membrane distillation was proposed to enrich the fermentation broth with BDO upon vaporization of water. $^{[12]}$ Liquid-liquid extraction into an organic solvent attracted significant attention, although low partition coefficients of BDO were usually observed due to the high hydrophilicity of the diol. For example, biocompatible oleyl alcohol enables in situ recovery of BDO from a broth during fermentation. ${ }^{[13]}$ 1-Butanol has been highlighted as a suitable solvent for BDO extraction because partitioning of BDO into 1-butanol (partition coefficient is ca. 1) is higher than that into other conventional organic solvents, although 1-butanol is partly miscible with water. ${ }^{[14]}$ The addition of salts into the aqueous phase improves the partition coefficient to 5.2 , owing to a salting-out effect. $^{[14]}$ The organic phase obtained after extraction can be concentrated by pervaporation with preferential permeation of water and 1-butanol. ${ }^{[15]}$

Aqueous two-phase extraction (ATPE) presents another method for postsynthetic ${ }^{[16]}$ or even in situ ${ }^{[17]}$ recovery of BDO. ATPE is based on the formation of two phases upon addition of two polymers (polyethylene glycol (PEG) and dextran), ${ }^{[16]}$ or a mixture of a salt and an alcohol (17-25 wt \% $\mathrm{KH}_{2} \mathrm{PO}_{4}+21-$ $24 \mathrm{wt} \%$ ethanol, ${ }^{[18]} 20 \mathrm{wt} \%\left(\mathrm{NH}_{4}\right)_{2} \mathrm{SO}_{4}+34 \mathrm{wt} \%$ isopropanol, ${ }^{[19]}$ $16 \mathrm{wt} \%\left(\mathrm{NH}_{4}\right)_{2} \mathrm{SO}_{4}+32 \mathrm{wt} \%$ ethanol $\left.{ }^{[20]}\right)$ to an aqueous solution of BDO. ATPE enables high partition coefficients of up to $28.34,{ }^{[18 a]}$ although utilization of highly concentrated solutions of salts requires corrosion-resistant equipment. Moreover, the recovery of salts from a highly polar medium can be challenging. Nevertheless, isolation of ammonium sulfate upon addition of methanol as an antisolvent was reported. ${ }^{[19,20]}$

Reactive extraction of BDO in the form of acetals by using butyraldehyde ${ }^{[21]}$ or formaldehyde ${ }^{[22]}$ was proposed. In the presence of acids, BDO reacts with aldehydes to form acetals that collect in the top oil phase, which can be separated. ${ }^{[22]} \mathrm{Hy}$ drolysis of acetals in the presence of an acid catalyst during reactive distillation releases $\mathrm{BDO} .{ }^{[21]}$ Efficient extraction of BDO in the form of acetals and recovery of the diol requires the addition of $0.5 \mathrm{M} \mathrm{HCl}$ or $\mathrm{H}_{2} \mathrm{SO}_{4}$ as catalysts, which results in the necessity for corrosion-resistant equipment and in the formation of acidic waste streams. ${ }^{[21]}$ Reactive extraction of BDO from fermentation broths was performed after esterification with formic and acetic acid in the presence of $\mathrm{H}_{2} \mathrm{SO}_{4}$ as a catalyst. Pyrolysis of the obtained esters yields 1,3butadiene. ${ }^{[23]}$

Herein, we propose a method for the recovery of BDO from fermentation broths by anionic extraction, utilizing reversible esterification with phenylboronates, as shown in Figure 1. Anionic extraction with phenylboronates has been investigated for the recovery and separation of monosaccharides, ${ }^{[24]}$ as well as for the isolation of 1,2-propanediol from aqueous solutions. ${ }^{[25]}$ In the first step (extraction), BDO is extracted into an organic phase containing phenylboronic acid (PBA), Aliquat ${ }^{\bullet} 336$, and 1-octanol as a diluent. An anionic complex, BDO-PBA-OH, and a

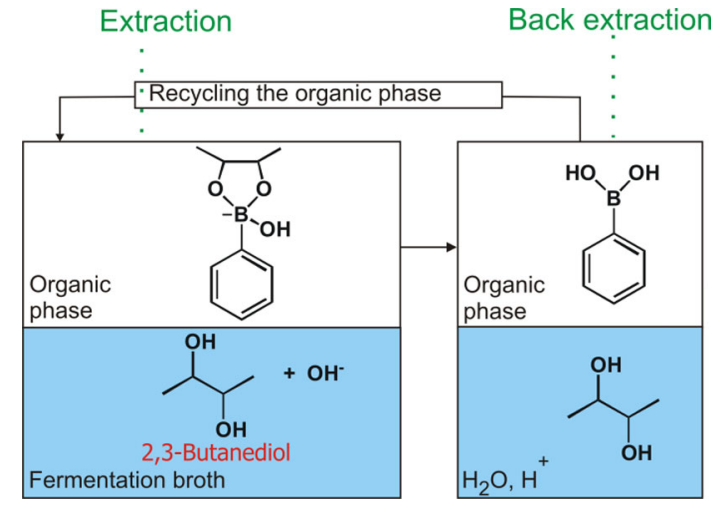

Figure 1. Isolation of BDO from fermentation broth through anionic extraction by using phenylboronates.

bulky cation of Aliquat 336 form an ion pair in the organic medium. BDO recovery is performed upon back-extraction with an acidified solution. The organic phase can be reused for the extraction. The recovered bio-BDO can be applied for the synthesis of MEK, whereas an original fermentation broth cannot. The results are discussed below in the context of challenges with water-based (bio)catalysis.

\section{Results and Discussion}

A commercially available solution of BDO and real fermentation broths were investigated. The concentrations of BDO and percentage of isomers are provided in Table 1. The commercial BDO comprised $75 \%$ meso-BDO and $25 \%$ of a mixture of $(2 R, 3 R)$ - and $(2 S, 3 S)-\mathrm{BDO}$, which is referred to as rac-BDO. Fermentation broths $\mathrm{FB}-1, \mathrm{FB}-2$, and $\mathrm{FB}-3$ presented solutions of either meso- or rac-BDO, whereas $\mathrm{FB}-4$ contained a mixture of them. In addition to BDO, the fermentation broths contained other organic compounds, such as glucose, acetoin, pyruvate, and ethanol. Detailed compositions of the fermentation broths are shown in Table $1 \mathrm{~S}$ in the Supporting Information.

\section{Extraction of BDO: Composition of the extracted species}

Anionic extraction of $\mathrm{BDO}$ can be described by Equation (1) (see below), that is, a chemical reaction between PBA, BDO, and a hydroxyl anion, leading to the formation of an anionic

\begin{tabular}{|c|c|c|c|c|c|}
\hline Entry & Abbreviation & Microorganism & $\begin{array}{l}\text { BDO concentration } \\
{\left[\mathrm{gL}^{-1}\right]}\end{array}$ & $\begin{array}{l}\text { meso-BDO } \\
{[\%]}\end{array}$ & $\begin{array}{l}\text { rac-BDO } \\
{[\%]}\end{array}$ \\
\hline \multicolumn{6}{|c|}{ commercial BDO } \\
\hline 1 & - & - & pure & 75 & 25 \\
\hline \multicolumn{6}{|c|}{ fermentation broths } \\
\hline 2 & FB-1 & L. lactis & 15.8 & 100 & 0 \\
\hline 3 & FB-2 & L. lactis & 24.0 & 100 & 0 \\
\hline 4 & FB-3 & P. polymyxa & 26.9 & 0 & 100 \\
\hline 5 & FB-4 & B. licheniformis ${ }^{[b]}$ & 84.3 & 47 & 53 \\
\hline
\end{tabular}


complex designated as BDO-PBA-OH. According to data reported in the literature, anionic complexes of vic-diols with phenyl boronates are especially stable. ${ }^{[26]}$

Indeed, the addition of $\mathrm{NaOH}$ to an aqueous medium facilitates the extraction of BDO (Table 2, entries 1-3). Interestingly, a higher percentage of rac-BDO than that of meso-BDO is extracted upon addition of $\mathrm{NaOH}$. This can be explained by the higher stability of complexes composed of cis-diols rather than those of trans-diols.

\begin{tabular}{|llllll|}
\hline \multicolumn{3}{|c|}{ Table 2. Results of anionic extraction of commercial BDO. ${ }^{\text {[a] }}$} \\
Entry & Additive & $\left.\begin{array}{c}\text { Additive concen- } \\
\text { tration [mol L }\end{array}{ }^{-1}\right]$ & \multicolumn{4}{c|}{ Extracted BDO [\%] } \\
\hline 1 & $\mathrm{NaOH}$ & 0.50 & 72 & 93 & 77 \\
2 & $\mathrm{NaOH}$ & 0.20 & 35 & 76 & 45 \\
3 & $\mathrm{NaOH}$ & 0.06 & 18 & 55 & 27 \\
4 & - & - & 18 & 18 & 18 \\
5 & $\mathrm{H}_{2} \mathrm{SO}_{4}$ & 1.05 & 30 & 67 & 39 \\
6 & $\mathrm{H}_{2} \mathrm{SO}_{4}$ & 2.05 & 33 & 71 & 42 \\
7 & $\mathrm{H}_{2} \mathrm{SO}_{4}$ & 5.15 & 44 & 80 & 52 \\
\hline
\end{tabular}

[a] Extraction conditions: $0.5 \mathrm{M} \mathrm{BDO}\left(4 \mathrm{~mL}, 45 \mathrm{gL}^{-1}\right)$ and additive (aqueous phase), $1 \mathrm{M}$ PBA ; $1 \mathrm{M}$ Aliquat 336 , and 1-octanol $(4 \mathrm{~mL}$, organic phase) under stirring at $750 \mathrm{rpm}$ for $1 \mathrm{~h}$ at RT.

Extraction of BDO without any additive results in poor extraction with the same partitioning for meso- and rac-BDO (Table 2, entry 4). Unexpectedly, the addition of sulfuric acid to the aqueous phase facilitated BDO transfer into the organic phase (Table 2, entries 5-7). The formation of $\mathrm{BDO}-\mathrm{PBA}-\mathrm{OH}$ complexes [Eq. (1)] under acidic conditions is highly unlikely. Therefore, we presumed the formation of a complex between BDO and PBA, abbreviated as BDO-PBA, according to Equation (2).
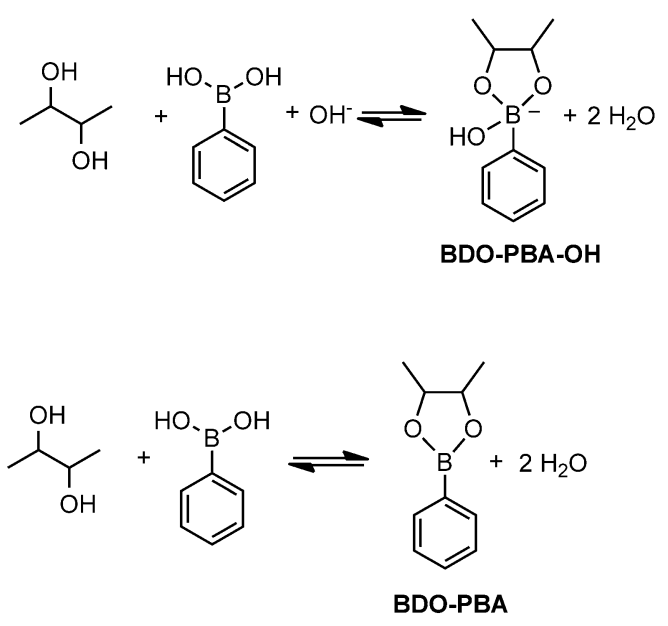

Complexes between PBA and diols undergo hydrolysis in the aqueous phase, although their formation in organic media was reported. ${ }^{[26]}$ Nevertheless, complexes between PBA and diols [Eq. (2)] are much less investigated than the complexes between phenylboronates and diols [Eq. (1)].
The composition of the extracted species was studied by NMR spectroscopy (Figure 2). First, the physical extraction of $\mathrm{BDO}$ into the organic phase was considered. An aqueous solution of $\mathrm{BDO}$ was allowed to stir with an organic phase comprised of $\mathrm{CDCl}_{3}$ and Aliquat ${ }^{\oplus} 336$. The NMR spectrum of the organic phase after extraction exhibited resonance signals corresponding to meso- and rac-BDO. ${ }^{[23]}$ Anionic extraction of BDO in the presence of $\mathrm{NaOH}$ resulted in the emergence of eight additional resonance signals, which were assigned to the complexes of meso- and rac-BDO with phenylboronate. Interestingly, introducing an asymmetrical center (a boron atom) results in lifting of the degeneracy in carbon chemical shifts corresponding to $-\mathrm{CH}_{3}$ and $-\mathrm{CH}$ groups. The ${ }^{11} \mathrm{~B}$ NMR spectrum of the organic phase after extraction from basic solutions exhibits a sole signal at $\delta=7 \mathrm{ppm}$, which indicates $\mathrm{sp}^{3}$-hybridization of boron (Figure $2 \mathrm{~S}$ in the Supporting Information). Additionally, the presence of negatively charged complexes of BDO-PBA$\mathrm{OH}$ was proven by ESI-MS. The mass spectrum of an organic phase after extraction exhibits a characteristic signal at $\mathrm{m} / \mathrm{z}$ 193 (Figure 3S in the Supporting Information). Interestingly, signals with high $\mathrm{m} / \mathrm{z}$ of up to 1100 were observed in the mass spectrum. The appearance of these signals can be explained by agglomeration of the amphiphilic Aliquat ${ }^{\oplus} 336$ ion pairs. Previously, Broekhuis et al. proposed the formation of such reverse micelles upon reactive extraction of 1,2-propanediol with phenylboronate. ${ }^{[25]}$ Thus, BDO is transferred into the organic phase as a mixture of complexes with phenylboronate and as physically extracted free BDO (Figure 2).

The addition of $\mathrm{H}_{2} \mathrm{SO}_{4}$ to the aqueous phase upon extraction results in a changed NMR spectrum: signals corresponding to free meso- and rac-BDO vanish and new resonances at $\delta=$ $16.6,20.9,75.9$, and $80.7 \mathrm{ppm}$ appear. Notably, already in the presence of $\mathrm{H}_{2} \mathrm{SO}_{4}$ in as low concentrations as $50 \mathrm{~mm}$, nearly no free BDO was detected in the organic medium (Figure $4 \mathrm{~S}$ in the Supporting Information). The new resonances were assigned to the complexes of meso- and rac-BDO with PBA depicted in Figure 2. The ${ }^{11} \mathrm{~B}$ NMR spectrum of the organic phase after extraction from acidic solutions contains one broad signal at $\delta=31 \mathrm{ppm}$, which corresponds to the presence of $\mathrm{sp}^{2}$ hybridized boron (Figure $2 S$ in the Supporting Information). Complexation between BDO and PBA upon extraction under acidic conditions was further studied by GC-MS. GC analysis of the organic phase after extraction from the acidic solution of BDO revealed the presence of two new peaks with similar retention times of 17.3 and $17.8 \mathrm{~min}$ (Figure $5 \mathrm{~S}$ in the Supporting Information). These peaks were not present on the chromatogram of the organic phase before extraction. A GC-MS investigation showed that these two peaks contained a characteristic signal at $m / z 176$ that could be assigned to meso-BDOPBA and rac-BDO-PBA complexes (Figure $6 \mathrm{~S}$ in the Supporting Information). In summary, BDO is reactively extracted upon addition of $\mathrm{H}_{2} \mathrm{SO}_{4}$ in the aqueous phase owing to the formation of PBA-BDO complexes [Eq. (2) and Figure 2]. The formation of such complexes with $\mathrm{sp}^{2}$-boron hybridization has been previously reported for glycosides upon transportation through a liquid membrane containing 3-(1-adamontylcarboxamido)phe- 

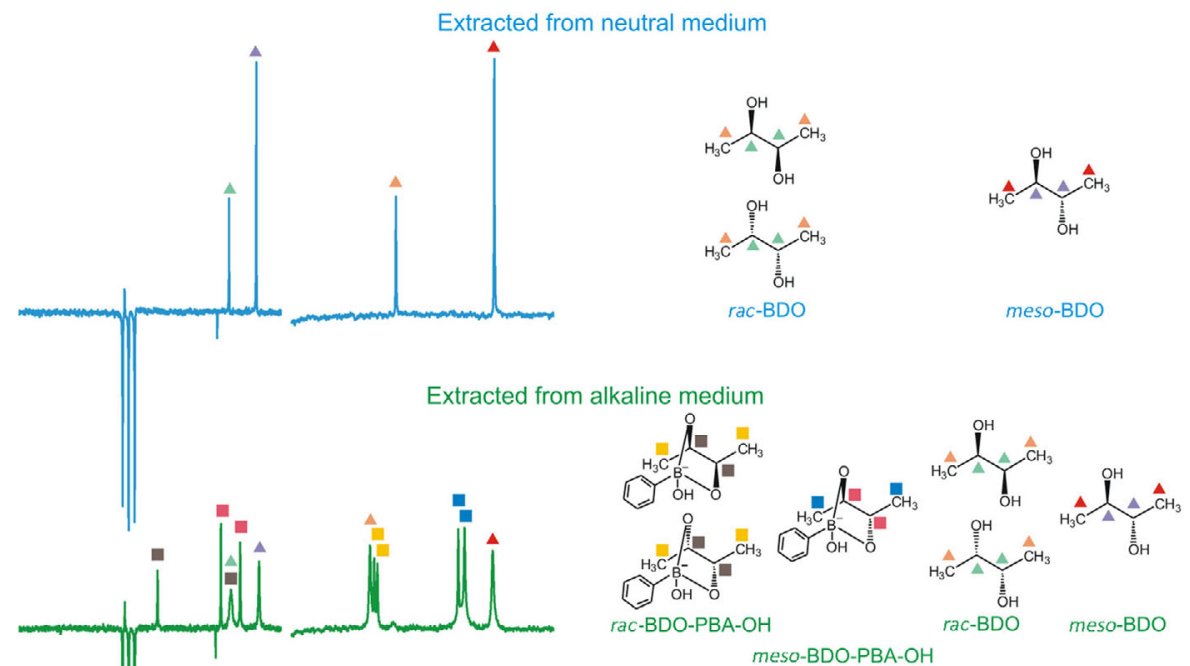

meso-BDO-PBA-OH

xtracted from acidic medium

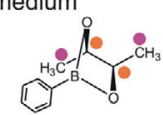
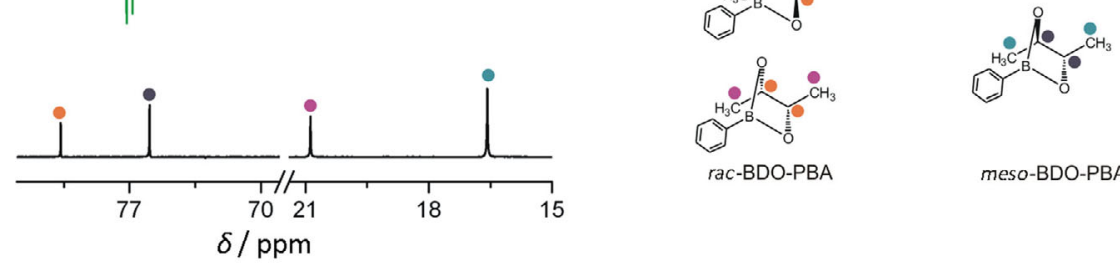

rac-BDO-PBA

meso-BDO-PBA

Figure 2. Assignment of NMR signals observed upon extraction of BDO (top), anionic extraction of BDO with phenylboronate (middle), and extraction of BDO due to complexation with PBA (bottom).

nylboronic acid. These complexes are very unstable in the presence of water and exist only in an organic phase. ${ }^{[26]}$

\section{Optimization of extraction and back-extraction conditions for fermentation broths}

According to the results in Table 2, the presence of $\mathrm{NaOH}$ in amounts at least equimolar to the amount of BDO is required to achieve good extraction results. Excess $\mathrm{NaOH}$ indeed facilitates extraction by shifting the equilibrium of Equation (1) to the right (Table 3, entries 1-3). Excess $\mathrm{NaOH}$ is not desirable from a practical point of view because it leads to higher costs and the additional generation of waste. Moreover, the utilization of an equimolar amount of $\mathrm{NaOH}$ already results in a rather high percentage of extracted $\mathrm{BDO}$ of $77 \%$ when using a model solution of a commercial diol. In addition, titration of an aqueous phase after extraction showed that the amount of extracted BDO equaled the amount of extracted $\mathrm{OH}^{-}$species, which confirmed that the extraction mainly occurred due to complex formation according to Equation (1). Nevertheless, real fermentation broths usually contain other components that can influence extraction. ${ }^{[8,12]}$ Table 3 provides the results of $\mathrm{BDO}$ extraction from real fermentation broths. Fermentation broth FB-1 exhibited the lowest percentage of extracted BDO of $20-25 \%$. This can be explained by a high glucose content in FB-1: it comprised 30.7 and $19.8 \mathrm{gL}^{-1}$ glucose and BDO, respectively (Table $1 \mathrm{~S}$ in the Supporting Information). In the presence of alkali, glucose yields a complex mixture of acidic products as a result of isomerization, cleavage, and dehydra-

\begin{tabular}{|c|c|c|c|c|c|c|}
\hline \multirow[t]{2}{*}{ Entry } & \multirow[t]{2}{*}{ BDO solution } & \multirow{2}{*}{$\begin{array}{l}\mathrm{NaOH} / \mathrm{BDO}^{[\mathrm{b}]} \\
{[\mathrm{mol} / \mathrm{mol}]}\end{array}$} & \multicolumn{3}{|c|}{ Extracted BDO [\%] } & \multirow{2}{*}{$\begin{array}{l}\text { Neutralized } \mathrm{OH}^{-} \\
\text {extracted } \mathrm{BDO}^{[\mathrm{c}]} \\
{[\mathrm{mol} / \mathrm{mol}]}\end{array}$} \\
\hline & & & meso & rac & total & \\
\hline 1 & commercial & 2 & 84 & 93 & 86 & 0.9 \\
\hline 2 & commercial & 1.5 & 82 & 93 & 85 & 1.0 \\
\hline 3 & commercial & 1 & 72 & 93 & 77 & 0.9 \\
\hline 4 & FB-1 & 2 & 25 & - & 25 & 5.7 \\
\hline 5 & FB-1 & 1.5 & 22 & - & 22 & 4.5 \\
\hline 6 & FB-1 & 1 & 20 & - & 20 & 3.1 \\
\hline 7 & FB-2 & 2 & 73 & - & 73 & 1.5 \\
\hline 8 & FB-2 & 1.5 & 57 & - & 57 & 1.7 \\
\hline 9 & FB-2 & 1 & 34 & - & 34 & 1.8 \\
\hline 10 & FB-3 & 2 & - & 93 & 93 & 1.6 \\
\hline 11 & FB-3 & 1.5 & - & 84 & 84 & 1.5 \\
\hline 12 & FB-3 & 1 & - & 68 & 68 & 1.1 \\
\hline 13 & FB-4 & 2 & 63 & 84 & 74 & 1.1 \\
\hline 14 & FB-4 & 1.5 & 66 & 87 & 77 & 1.0 \\
\hline 15 & FB-4 & 1 & 47 & 89 & 68 & 0.9 \\
\hline
\end{tabular}

[a] Extraction conditions: a solution $(4 \mathrm{~mL})$ containing $\mathrm{BDO}$ and $\mathrm{NaOH}$ (aqueous phase); 1 м PBA, 1 M Aliquat 336 , and 1-octanol ( $4 \mathrm{~mL}$, organic phase) under stirring at $750 \mathrm{rpm}$ for $1 \mathrm{~h}$ at RT. [b] Molar ratio of $\mathrm{NaOH}$ and $\mathrm{BDO}$ adjusted in aqueous phase prior to the extraction. [c] Molar ratio of $\mathrm{OH}^{-}$neutralized during the extraction [ideally due to the complex formation according to the Eq. (1)] to the amount of extracted BDO. 
tion reactions. ${ }^{[27]}$ Formation of these organic acids result in partial neutralization of $\mathrm{NaOH}$. In addition, glucose itself is a polyol, which is coextracted together with BDO. Extraction of BDO from FB-2-FB-4 appeared to be more efficient, compared with FB-1, although somewhat less efficient than the use of a commercial solution of BDO. In addition to BDO, glycerol was also coextracted from the fermentation broths (Table $2 \mathrm{~S}$ in the Supporting Information). No extraction of acetoin was observed under the applied conditions.

Recovery of a polyol after anionic extraction with phenylboronates is typically performed upon back-extraction into an acidic medium. Addition of an acid shifts the equilibrium of Equation (1) to the left and a polyol is released. This approach appeared to be successful for the recovery of saccharides. ${ }^{[24]}$ However, as shown above, BDO also forms a complex with PBA under acidic conditions according to Equation (2). Therefore, excess acid was expected to facilitate the extraction of $\mathrm{BDO}$ due to the formation of a BDO-PBA complex.

The amount of back-extracted BDO indeed depends on the concentration of the acid used (Figure 3). Complete results of

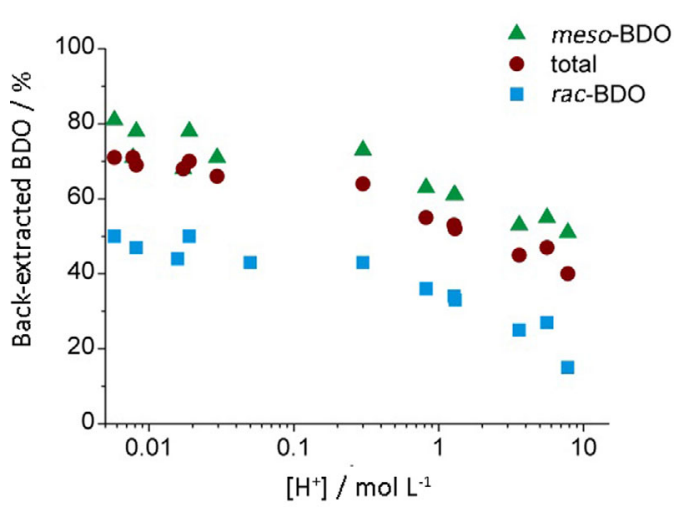

Figure 3. Percentage of back-extracted BDO as a function of the acidity of the aqueous medium after extraction. Extraction conditions: a solution of $\mathrm{H}_{2} \mathrm{SO}_{4}$ (4 mL; aqueous phase), an organic phase (4 mL) after extraction of commercial or bio-BDO, under stirring at $750 \mathrm{rpm}$ for $30 \mathrm{~min}$ at RT.

the extraction and back-extraction are provided in Table $3 \mathrm{~S}$ in the Supporting Information. The best recovery of BDO was achieved by performing back-extraction in slightly acidic medium with $\left[\mathrm{H}^{+}\right]$of less than $0.01 \mathrm{M}$. The percentage of backextracted BDO depends on the stereochemistry: meso-BDO is recovered more readily compared with rac-BDO due to lower stability of a complex between phenylboronate and the former stereoisomer. In general, no difference in back-extraction of commercial BDO and bio-BDO was observed (Table $3 \mathrm{~S}$ in the Supporting Information). Notably, the amount of recovered BDO is limited to about $70-80 \%$ when using the same volumes of organic and aqueous phases. The recovery can nevertheless be improved up to $90 \%$ when using an excess of aqueous phase (Table $3 \mathrm{~S}$ in the Supporting Information). Figure $7 \mathrm{~S}$ in the Supporting Information shows HPLC traces of fermentation broths and refined solutions after extraction and backextraction.
Recycling of the organic phase was performed by repeating extraction and back-extraction experiments. The organic phase was treated with a phosphate buffer after each recycling run. A somewhat declining BDO capacity of the organic phase was observed upon reuse. This can be explained by a partial leaching of boron upon extraction and back-extraction (Figure 4).

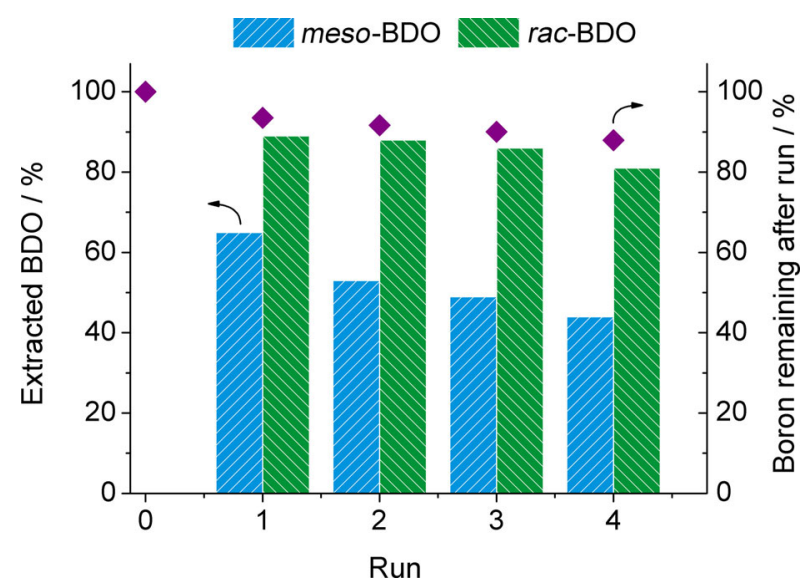

Figure 4. Repeated use of an organic phase for extraction of BDO and amount of boron remaining in the organic phase after each run. Extraction conditions: a solution $(4 \mathrm{~mL}$ ) containing $0.5 \mathrm{M} \mathrm{BDO}$ and $0.5 \mathrm{M} \mathrm{NaOH}$ (aqueous phase), $1 \mathrm{M}$ PBA ; $1 \mathrm{M}$ Aliquat ${ }^{\circ} 336$, and 1-octanol (4 mL, organic phase) under stirring at $750 \mathrm{rpm}$ for $1 \mathrm{~h}$ at RT.

\section{Conversion of BDO into MEK}

Conversion of BDO into MEK takes place through a pinacol rearrangement in the presence of an acidic catalyst. The catalytic activity of molecular acids, such as $\mathrm{H}_{2} \mathrm{SO}_{4}{ }^{[28]}$ or $\mathrm{H}_{3} \mathrm{PO}_{4}{ }^{[29]}$ for this reaction has been known for a long time. A reduction of corrosion potential and a decrease of acidic waste streams can be achieved by application of solid catalysts, for example, sulfonated alumina and silica-alumina ${ }^{[30]}$ or boric acid modified HZSM-5 zeolites. ${ }^{[4]}$ Herein, we focused on the transformation of BDO into MEK in the presence of sulfuric acid. First, the possibility of using a fermentation broth directly for MEK synthesis was investigated. Commercial BDO could be readily converted into MEK (Figure 5), whereas a mixture of fermentation broth with sulfuric acid yielded no MEK, but a black precipitate of humins (Figure $8 \mathrm{~S}$ in the Supporting Information). This result contradicts previous publications reporting the successful direct application of fermentation broths for MEK synthesis. ${ }^{[28,30]}$ The efficiency of BDO dehydration to MEK appears to depend significantly on the composition of the fermentation broth and probably on the composition of the catalyst. Herein, the other components of the fermentation broths gave rise to humins in the presence of acid and at elevated temperature (Table $1 \mathrm{~S}$ in the Supporting Information).

However, after the isolation of BDO through extraction with phenylboronate, bio-BDO can be converted into MEK as efficiently as commercial BDO (Figure 5). Under the reaction conditions, BDO was also converted into isobutyraldehyde in minor yields of $1-3 \% .{ }^{[29]}$ In addition, the formation of condensation products owing to the aldol reaction was observed. At 


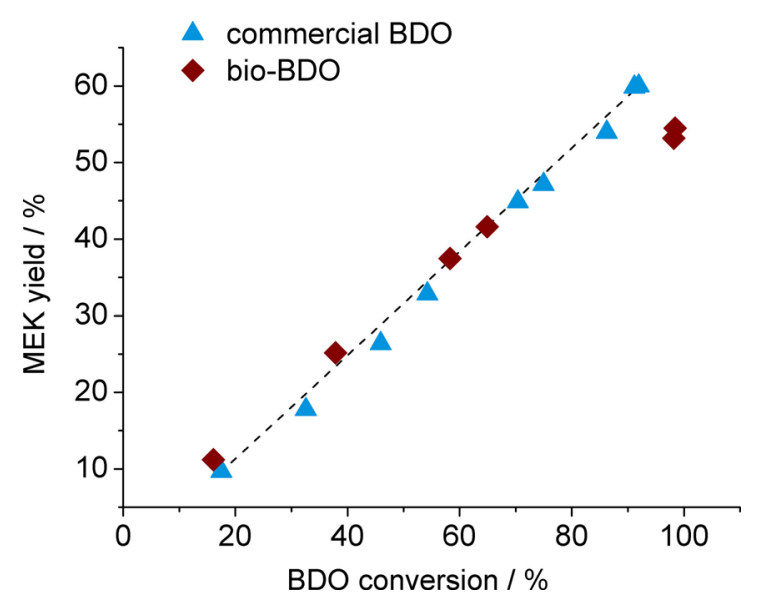

Figure 5. Yield of MEK versus $\mathrm{BDO}$ conversion at $180^{\circ} \mathrm{C}$ in the presence of $\mathrm{H}_{2} \mathrm{SO}_{4}$. Bio-BDO was applied after purification of FB-4 by anionic extraction with phenylboronate.

conversions of $\mathrm{BDO}$ higher than $90 \%$, the formation of a second liquid phase took place. According to the results of GC-MS, this liquid phase contained condensation products of the carbonyl compounds (results not shown). The presence of glycerol in minor amounts after purification (Figure 7S in the Supporting Information) apparently does not impact the selectivity towards MEK.

A critical comparison of the proposed method of MEK synthesis based on bio-BDO with previously proposed approaches is of great interest. According to the recent comparative study of Penner et al., the overall process efficiency largely depends on the efficiency of BDO recovery from the fermentation broth. In this respect, the material efficiency and energy demand were indicated as parameters to assess the overall efficiency of the separation. ${ }^{[31]}$ It is crucial to mention that the importance of energy demand is dramatically dependent on the scale of the production. Energy-intensive separation methods are feasible at large chemical plants owing to efficient heat integration. However, significant energy input can especially affect small- and medium-sized enterprises with low degrees of heat integration. ${ }^{[32]}$ In this regard, energy-demanding distillation of $\mathrm{BDO}$ can be implemented for the large-scale companies, but is less suitable for small-scale biorefineries. Because the method proposed herein for BDO recovery does not include any heating operations, it is expected to be energy efficient and appropriate for small-scale refineries. Nevertheless, further analysis for the estimation of the industrial applicability of the proposed method for MEK synthesis is required.

\section{Conclusions}

Herein, we demonstrate the recovery of BDO from a complex fermentation broth by means of anionic extraction through complexation with phenylboronates. This method enables the selective recovery of BDO from the broths, although other components containing a 1,2-diol motif, such as glycerol or glucose, can be coextracted. Gaining an insight into processes of extraction and back-extraction allowed us to optimize their conditions. Up to $72-93 \%$ BDO can be extracted and up to $80-90 \%$ recovered under the optimized conditions. The organic phase was reused four times with only a minor decrease of the BDO capacity and moderate leaching of boron into the aqueous phase. Refined bio-BDO could be efficiently used for the synthesis of MEK, whereas the fermentation broths could not due to the formation of humins. The obtained results indicate that anionic extraction is a promising method for the recovery of BDO. Further research can be focused on reducing the amount of organic solvents and molecular acids/bases used as auxiliary chemicals to facilitate complexation. Moreover, the sustainability of MEK synthesis can be further improved through the utilization of a solid acidic catalyst. In situ removal of the product by reactive distillation presents another possibility for process intensification.

\section{Experimental Section}

\section{Chemicals}

2,3-Butanediol (98\%), Aliquat 336 (chloride form), and 1-octanol (>99\%) were purchased from Sigma-Aldrich. Deuterium oxide (99.9\%) and $\mathrm{CDCl}_{3}$ (99.9\%) were obtained from Deutero. $\left[D_{6}\right]$ Benzene $(99.9 \%)$ and $\left[D_{6}\right]$ acetone $(99.8 \%)$ were purchased from abcr. Microgranulate sodium hydroxide $(98.8 \%)$, methanol $(99.8 \%)$, sulfuric acid $(>95 \%)$, and a standard solution of hydrochloric acid $(0.1 \mathrm{M})$ were obtained from Chemsolute. PBA $(98 \%)$ was obtained from ChemPUR. Sodium dihydrogen phosphate monohydrate (Reag. Ph. Eur.) was provided by Merck. All solutions were prepared in distilled water.

\section{Strain construction}

L. lactis pNZ_BD1 was a derivative of the double lactate dehydrogenase-deficient strain $\mathrm{NZ9000} \Delta / d h \Delta / d h B$ that overexpressed the genes coding for $\alpha$-acetolactate synthase (als, Ilmg_1309) and acetoin reductase (butA, Ilmg_1641) from L. lactis MG1363. ${ }^{[33]}$ The als and but $A$ genes were cloned into the nisin-inducible expression vector pNZ8048, ${ }^{[34]}$ as previously described ${ }^{[35]}$ to provide plasmid pNZ_BD1. The plasmid was obtained and maintained in NZ9000. ${ }^{[34]}$ The gene sequences of pNZ_BD1 were verified by sequencing and

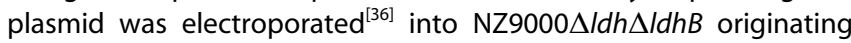
strain NZ9000 $\Delta / d h \Delta / d h B p N Z$ BD1 (herein denoted L. lactis pNZ_ $\mathrm{BD} 1)$.

\section{Fermentation}

L. lactis pNZ_BD1 was cultivated in New Brunswick BioFlo 110 bioreactors (Eppendorf, Hamburg, Germany) with a total volume of $1.3 \mathrm{~L}$ and a working volume of $0.5 \mathrm{~L}$. The temperature was maintained at $30^{\circ} \mathrm{C}$ and the $\mathrm{pH}$ value was set to 6.5 and controlled automatically with $4 \mathrm{M} \mathrm{NaOH}$. The aeration rate was set to $0.5 \mathrm{~L} \mathrm{~min}^{-1}$ $(1 \mathrm{vvm})$ and dissolved oxygen was kept at $40 \%$ by automatically adjusting the stirring rate between 250 and $1200 \mathrm{rpm}$. The fedbatch fermentations were conducted by using a chemically defined medium (CDM) ${ }^{[37]}$ and complex medium DifCo ${ }^{\mathrm{TM}}$ M17 Broth (BD, USA) referred to as $\mathrm{M} 17$. In the cultivations, glucose $\left(20 \mathrm{gL}^{-1}\right)$ was added from the beginning. The media were furthermore complemented with CM and hemin. One hour after inoculation, nisin was added to induce the expression of the genes for BDO production. Three times during $45 \mathrm{~h}$ of fermentation, glucose $\left(20 \mathrm{gL}^{-1}\right)$ was 
added (after 15, 17, and $23 \mathrm{~h}$ ). Precultures were grown in $500 \mathrm{~mL}$ shake flasks filled with the respective medium $(50 \mathrm{~mL})$. They were inoculated with a cryoculture $(250 \mu \mathrm{L})$ and incubated overnight at $30^{\circ} \mathrm{C}$. The starting optical density at $\lambda=600 \mathrm{~nm}\left(\mathrm{OD}_{600}\right)$ was set to 0.25 .

Cultivations of $B$. licheniformis DSM 8785 and P. polymyxa DSM 365 were conducted in a complex medium, according to a procedure reported by Nakashimada et al. ${ }^{[38]}$ The medium contained yeast extract $\left(5 \mathrm{~g} \mathrm{~L}^{-1}\right)$, tryptone $\left(5 \mathrm{~g} \mathrm{~L}^{-1}\right), \mathrm{K}_{2} \mathrm{HPO}_{4}\left(7 \mathrm{~g} \mathrm{~L}^{-1}\right), \mathrm{KH}_{2} \mathrm{PO}_{4}\left(5.5 \mathrm{~g} \mathrm{~L}^{-1}\right)$, $\left(\mathrm{NH}_{4}\right)_{2} \mathrm{SO}_{4} \quad\left(1 \mathrm{~g} \mathrm{~L}^{-1}\right), \quad \mathrm{MgSO}_{4} \cdot 7 \mathrm{H}_{2} \mathrm{O} \quad\left(0.25 \mathrm{~g} \mathrm{~L}^{-1}\right), \quad \mathrm{Na}_{2} \mathrm{MoO}_{4} \cdot 2 \mathrm{H}_{2} \mathrm{O}$ $\left(0.12 \mathrm{~g} \mathrm{~L}^{-1}\right), \mathrm{CaCl}_{2} \cdot 2 \mathrm{H}_{2} \mathrm{O}\left(0.021 \mathrm{~g} \mathrm{~L}^{-1}\right), \mathrm{Co}\left(\mathrm{NO}_{3}\right)_{2} \cdot 6 \mathrm{H}_{2} \mathrm{O}\left(0.029 \mathrm{~g} \mathrm{~L}^{-1}\right)$, $\left(\mathrm{NH}_{4}\right)_{2} \mathrm{Fe}\left(\mathrm{SO}_{4}\right)_{2} \cdot 6 \mathrm{H}_{2} \mathrm{O} \quad\left(0.039 \mathrm{~g} \mathrm{~L}^{-1}\right)$, nicotinic acid $\left(0.002 \mathrm{~g} \mathrm{~L}^{-1}\right)$, $\mathrm{Na}_{2} \mathrm{SeO}_{3} \quad\left(0.0002 \mathrm{gL}^{-1}\right), \quad \mathrm{NiCl}_{2} \cdot 6 \mathrm{H}_{2} \mathrm{O} \quad\left(0.00005 \mathrm{~g} \mathrm{~L}^{-1}\right), \quad \mathrm{MnCl}_{2} \cdot 4 \mathrm{H}_{2} \mathrm{O}$ $\left(0.005 \mathrm{~g} \mathrm{~L}^{-1}\right), \mathrm{H}_{3} \mathrm{BO}_{3}\left(0.001 \mathrm{~g} \mathrm{~L}^{-1}\right), \quad \operatorname{AIK}\left(\mathrm{SO}_{4}\right)_{2} \cdot 12 \mathrm{H}_{2} \mathrm{O}\left(0.0002 \mathrm{~g} \mathrm{~L}^{-1}\right)$, $\mathrm{CuCl}_{2} \cdot 2 \mathrm{H}_{2} \mathrm{O}\left(0.00001 \mathrm{gL}^{-1}\right)$, and $\mathrm{Na}_{2}$ EDTA. $2 \mathrm{H}_{2} \mathrm{O}\left(0.0055 \mathrm{gL}^{-1}\right)$. Glucose was added at concentrations of $180 \mathrm{~g} \mathrm{~L}^{-1}$ for $B$. licheniformis and $70 \mathrm{~g} \mathrm{~L}^{-1}$ for $P$. polymyxa. The medium was completed from different stock solutions that were sterilized separately. The cultivation was performed at $37^{\circ} \mathrm{C}$ in $250 \mathrm{~mL}$ shake flasks that were placed in an orbital shaker with a shaking frequency of $100 \mathrm{rpm}$ and a shaking diameter of $5 \mathrm{~cm}$. As preculture, the medium $(20 \mathrm{~mL})$ was inoculated with a cryostock $(200 \mu \mathrm{L})$. This culture was used to inoculate $40 \mathrm{~mL}$ per flask at an $\mathrm{OD}_{600}$ of 0.1 as the main culture.

\section{Extraction}

The organic phase typically contained $1 \mathrm{~m}$ PBA and $1 \mathrm{~m}$ Aliquat 336 dissolved in 1-octanol. The organic phase was pretreated prior to extraction by stirring with $1 \mathrm{M} \quad \mathrm{NaH}_{2} \mathrm{PO}_{4}+\mathrm{Na}_{2} \mathrm{HPO}_{4}$ phosphate buffer at $\mathrm{pH}_{0} 7.5$ for $30 \mathrm{~min}$ at RT. In a typical extraction experiment, the organic phase $(4 \mathrm{~mL})$ and an aqueous phase $(4 \mathrm{~mL})$ were stirred $(750 \mathrm{rpm})$ for $1 \mathrm{~h}$ at RT. Thereafter, the phases were separated by centrifugation for $1 \mathrm{~min}$ at $7000 \mathrm{rpm}$. After splitting the phases, back-extraction was performed: the organic phase $(4 \mathrm{~mL})$ after the extraction was stirred with $\mathrm{H}_{2} \mathrm{SO}_{4}(4 \mathrm{~mL})$ for $1 \mathrm{~h}$ at RT. Alternatively, back-extraction with monitoring of the final $\mathrm{pH}$ of the suspension was performed: The organic phase after extraction (4 mL) was mixed with $\mathrm{H}_{2} \mathrm{SO}_{4}(2 \mathrm{~mL})$. A pH electrode was immersed into the mixture and the $\mathrm{pH}$ value was adjusted under stirring through the dropwise addition of a $0.26 \mathrm{M}$ solution of $\mathrm{H}_{2} \mathrm{SO}_{4}$.

Model aqueous solutions containing commercial $\mathrm{BDO}$ and $\mathrm{NaOH}$ were utilized for optimization of the conditions for extraction and back-extraction, as well as to investigate complex compositions. A solution of $\mathrm{NaOH}$ was added to fermentation broths prior to extraction.

The $1 \mathrm{M} \quad \mathrm{NaH}_{2} \mathrm{PO}_{4}+\mathrm{Na}_{2} \mathrm{HPO}_{4}$ phosphate buffer was prepared through the dropwise addition of a $4 \mathrm{M}$ solution of $\mathrm{NaOH}$ to the solution of $\mathrm{NaH}_{2} \mathrm{PO}_{4}$ by using a Titroline alpha titrator unit (Schott) to reach the required $\mathrm{pH}$.

Concentrations of $\mathrm{NaOH}$ and $\mathrm{H}_{2} \mathrm{SO}_{4}$ in the solutions after extraction and back-extraction were determined by means of titration by using a Titroline alpha titrator unit (Schott). Leaching of PBA was studied by inductively coupled plasma optical emission spectroscopy (ICP-OES) analysis (Spectro Analytical Instruments) of boron in the aqueous phase.

For NMR spectroscopy investigations, typical extraction experiments were carried out. The aqueous phase was composed of a $0.5 \mathrm{M}$ solution of $\mathrm{BDO}$ in $\mathrm{D}_{2} \mathrm{O}$ with $\mathrm{NaOH}$ or $\mathrm{H}_{2} \mathrm{SO}_{4}$. The organic phase was prepared by dissolution of PBA $(0.5 \mathrm{M})$ and Aliquat 336 $(0.5 \mathrm{M})$ in $\mathrm{CDCl}_{3}$ or $\mathrm{C}_{6} \mathrm{D}_{6}$. The organic phase was pretreated prior to the extraction experiment: The organic phase was stirred with $0.5 \mathrm{M}$ phosphate buffer prepared in $\mathrm{D}_{2} \mathrm{O}(1: 1 \mathrm{v} / \mathrm{v})$ for $30 \mathrm{~min}$ at RT. After pretreatment, the phases were separated after centrifugation for $1 \mathrm{~min}$ at $7000 \mathrm{rpm}$. The extraction of BDO was performed under stirring at RT for $1 \mathrm{~h}$. After completing the extraction and separation of the phases, the organic phase was investigated by means of NMR spectroscopy. ${ }^{1} \mathrm{H}(400 \mathrm{MHz}),{ }^{13} \mathrm{C}(101 \mathrm{MHz})$, and ${ }^{11} \mathrm{~B}$ NMR $(96 \mathrm{MHz})$ spectra were recorded on Bruker spectrometers. Chemical shifts are reported in $\delta$ (ppm) units by using ${ }^{13} \mathrm{C}$ and residual ${ }^{1} \mathrm{H}$ signals from deuterated solvents as references. The ${ }^{11} \mathrm{~B}$ NMR spectra were referenced to $\mathrm{Et}_{2} \mathrm{O} \cdot \mathrm{BF}_{3}$ in $\mathrm{CDCl}_{3}$ as $\delta=0 \mathrm{ppm}$. Structures of complexes of BDO with PBA or phenylboronate were proposed based on the results of COSY, HSQC, HMBC, and APT ${ }^{13} \mathrm{C}$ NMR spectra. In addition, NMR spectroscopy investigations of $\mathrm{BDO}$ extracted from fermentation broths $\mathrm{FB}-2$ and $\mathrm{FB}-3$, that is, containing only meso- and rac-BDO, respectively, were carried out.

Samples for analysis by ESI-MS were prepared by using a typical extraction procedure. After separation of the phases, the organic phase was diluted 1:50 with 1-octanol. The diluted samples were injected into an LCMS-2020 liquid chromatograph mass spectrometer (Shimadzu) operating in both positive and negative ionization modes. The mass spectra were collected in the range of $\mathrm{m} / \mathrm{z} 50$ 2000 with a probe voltage of $4.5 \mathrm{kV}$ and Q-array radiofrequency (RF) voltage of $60 \mathrm{~V}$.

The samples for GC-MS were prepared according to a typical extraction procedure. The organic phase was diluted 1:10 with methanol and injected into a gas chromatograph equipped with a TRACE Ultra GC by Thermo Scientific with Rtx-5-Sil-MS column (30 m, inner diameter (ID) $=0.28 \mathrm{~mm}, d_{\mathrm{F}}=0.25 \mu \mathrm{m}, T=50-280^{\circ} \mathrm{C}$, 5 iso, $8^{\circ} \mathrm{Cmin}^{-1}$ ). For GC-MS measurements, a Varian-Cp 3800 device with a $1200 \mathrm{~L}$ Quadrupole MS/MS spectrometer was used.

\section{Conversion of BDO into MEK}

Experiments were carried out in a $45 \mathrm{~mL}$ Berghof autoclave equipped with a polytetrafluoroethylene (PTFE) inlet. Aqueous solutions ( $4 \mathrm{~mL}$ ) containing $\mathrm{BDO}$ and $\mathrm{H}_{2} \mathrm{SO}_{4}$ were charged into an autoclave, sealed, and pressurized with about $30 \mathrm{bar}\left(1 \mathrm{bar}=10^{5} \mathrm{~Pa}\right)$ nitrogen. The reactions were performed under stirring at $750 \mathrm{rpm}$ at $180^{\circ} \mathrm{C}$. The initial concentration of BDO was 0.25 or $0.5 \mathrm{M}$. The concentration of $\mathrm{H}_{2} \mathrm{SO}_{4}$ varied in the range of $0.05-0.18 \mathrm{M}$. The reaction was performed for 2-7 h. After the experiments, the reaction mixture was cooled in an ice bath and filtered through a polyamide syringe filter (Chromaphil, polyamide, pore size $0.2 \mu \mathrm{m}$ ).

Concentrations of $\mathrm{BDO}$, other components of fermentation broths, and the products of dehydration to MEK were determined by HPLC on a Shimadzu Prominence LC-20 system. The separation was performed by using two successively connected organic acid resin columns (CS-Chromatographie, $100 \mathrm{~mm} \times 8.0 \mathrm{~mm}$ and $300 \mathrm{~mm} \times 8.0 \mathrm{~mm})$ at $40^{\circ} \mathrm{C}$; the eluent $\left(\mathrm{CF}_{3} \mathrm{COOH}(154 \mu \mathrm{L})\right.$ in water

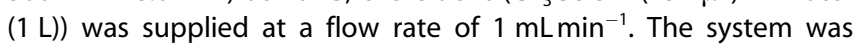
equipped with a refractive index (RI) detector.

\section{Acknowledgements}

We thank Prof. Dr. Regina Palkovits for useful discussions. We thank Noah Avraham for HPLC and ESI-MS measurements; Elke Biener, Hannelore Eschmann, and Wolfgang Falter for performing GC-MS measurements; Ines Bachmann-Remy for "B NMR spectroscopy measurements; and Heike Bergstein for ICP-OES analy- 
ses. This work was performed as part of the Cluster of Excellence "Tailor-Made Fuels from Biomass" funded by the Excellence Initiative by the German federal and state governments to promote science and research at German universities. I.D. thanks the Max Buchner Research Foundation for financial support.

\section{Conflict of interest}

The authors declare no conflict of interest.

Keywords: alcohols · anionic extraction - biocatalysis $\cdot$ boron . sustainable chemistry

[1] a) M. Voloch, N. Jansen, M. Ladisch, G. Tsao, R. Narayan, V. Rodwell in Comprehensive Biotechnology (Eds.: C. L. Cooney, A. E. Humphrey), Pergamon, New York, 1985, pp. 933-947; b) I. Delidovich, P. J. C. Hausoul, L. Deng, R. Pfützenreuter, M. Rose, R. Palkovits, Chem. Rev. 2016, 116 $1540-1599$.

[2] a) A.-P. Zeng, W. Sabra, Curr. Opin. Biotechnol. 2011, 22, 749-757; b) J. V. Haveren, E. L. Scott, J. Sanders, Biofuels Bioprod. Bioref. 2008, 2, 41-57.

[3] http://lanzatech.com.

[4] W. Zhang, D. Yu, X. Ji, H. Huang, Green Chem. 2012, 14, 3441-3450.

[5] F. Hoppe, B. Heuser, M. Thewes, F. Kremer, S. Pischinger, M. Dahmen, M. Hechinger, W. Marquardt, Int. J. Engine Res. 2016, 17, 16-27.

[6] S. K. Garg, A. Jain, Bioresour. Technol. 1995, 51, 103-109.

[7] B. G. Harvey, W. W. Merriman, R. L. Quintana, ChemSusChem 2016, 9, $1814-1819$.

[8] A. S. Afschar, C. E. Vaz Rossell, R. Jonas, A. Quesada Chanto, K. Schaller, J. Biotechnol. 1993, 27, 317-329.

[9] A. Alexakis, P. Mangeney, Tetrahedron: Asymmetry 1990, 1, 477-511.

[10] H. Gräfje, W. Körnig, H.-M. Weitz, W. Reiß, G. Steffan, H. Diehl, H. Bosche, K. Schneider, H. Kieczka in Ullmann's Encyclopedia of Industrial Chemistry, Wiley-VCH, Weinheim, 2000

[11] a) X.-J. Ji, H. Huang, P.-K. Ouyang, Biotechnol. Adv. 2011, 29, 351-364; b) Y. Jiang, W. Liu, H. Zou, T. Cheng, N. Tian, M. Xian, Microb. Cell Fact. 2014, 13, 165; c) Z.-L. Xiu, A.-P. Zeng, Appl. Microbiol. Biotechnol. 2008 78, 917-926.

[12] N. Qureshi, M. M. Meagher, R. W. Hutkins, Sep. Sci. Technol. 1994, 29, $1733-1748$

[13] a) M. Anvari, G. Khayati, J. Ind. Microbiol. Biotechnol. 2009, 36, 313-317; b) H. Pahlavanzadeh, G. Khayati, N. Ghaemi, E. Vasheghani-Farahani, Iran. J. Chem. Chem. Eng. 2012, 31, 59-63.

[14] Y. Y. Wu, K. Chen, J. W. Zhu, B. Wu, L. Ji, Y. L. Shen, Can. J. Chem. Eng. 2014, 92, $511-514$.
[15] a) P. Shao, A. Kumar, J. Membr. Sci. 2009, 339, 143-150; b) P. Shao, A. Kumar, J. Membr. Sci. 2009, 329, 160-168.

[16] S. Ghosh, T. Swaminathan, Chem. Biochem. Eng. Q. 2004, 18, 263-271.

[17] S. Ghosh, T. Swaminathan, Chem. Biochem. Eng. Q. 2003, 17, 319-325.

[18] a) B. Jiang, Z.-G. Li, J.-Y. Dai, D.-J. Zhang, Z.-L. Xiu, Process Biochem. 2009, 44, 112-117; b) J. Dai, Y. Zhang, Z. Xiu, Chin. J. Chem. Eng. 2011, $19,682-686$.

[19] L.-H. Sun, B. Jiang, Z.-L. Xiu, Biotechnol. Lett. 2009, 31, 371-376.

[20] Z. Li, H. Teng, Z. Xiu, Process Biochem. 2010, 45, 731-737.

[21] a) J. Hao, F. Xu, H. Liu, D. Liu, J. Chem. Technol. Biotechnol. 2006, 81, $102-108$; b) Y. Li, Y. Wu, J. Zhu, J. Liu, Y. Shen, J. Saudi Chem. Soc. 2016, 20, S495-S502.

[22] M. Senkus, Ind. Eng. Chem. 1946, 38, 913-916.

[23] J. Baek, T. Y. Kim, W. Kim, H. J. Lee, J. Yi, Green Chem. 2014, 16, 3501 3507.

[24] a) P. J. Duggan, Aust. J. Chem. 2004, 57, 291 - 299; b) I. Delidovich, R. Palkovits, Green Chem. 2016, 18, 5822-5830.

[25] R. R. Broekhuis, S. Lynn, C. J. King, Ind. Eng. Chem. Res. 1996, 35, $1206-$ 1214.

[26] G. T. Morin, M.-F. Paugam, M. P. Hughes, B. D. Smith, J. Org. Chem. 1994, 59, 2724-2728.

[27] a) J. M. de Bruijn, 1986; b) I. Delidovich, R. Palkovits, Catal. Sci. Technol. 2014, 4, 4322-4329.

[28] R. R. Emerson, M. C. Flickinger, G. T. Tsao, Ind. Eng. Chem. Prod. Res. Dev. $1982,21,473-477$

[29] E. R. Alexander, D. C. Dittmer, J. Am. Chem. Soc. 1951, 73, 1665-1668.

[30] A. V. Tran, R. P. Chambers, Biotechnol. Bioeng. 1987, 29, 343-351.

[31] D. Penner, C. Redepenning, A. Mitsos, J. Viell, Ind. Eng. Chem. Res. 2017 56, 3947-3957.

[32] R. C. Kolfschoten, M. E. Bruins, J. P. M. Sanders, Biofuels Bioprod. Biorefin. 2014, 8, 475-486.

[33] M. J. Gasson, J. Bacteriol. 1983, 154, 1 -9.

[34] O. P. Kuipers, P. G. G. A. de Ruyter, M. Kleerebezem, W. M. de Vos, J. Biotechnol. 1998, 64, 15-21.

[35] P. Gaspar, A. R. Neves, M. J. Gasson, C. A. Shearman, H. Santos, Appl. En viron. Microbiol. 2011, 77, 6826-6835.

[36] H. Holo, I. F. Nes in Electroporation Protocols for Microorganisms (Ed.: J. A. Nickoloff), Humana, Totowa, NJ, 1995, pp. 195-199.

[37] B. Poolman, W. N. Konings, J. Bacteriol. 1988, 170, 700-707.

[38] Y. Nakashimada, K. Kanai, N. Nishio, Biotechnol. Lett. 1998, 20, $1133-$ 1138.

Manuscript received: May 23, 2017

Revised manuscript received: June 23, 2017

Accepted manuscript online: June 26, 2017

Version of record online: $\mathbf{\square}$ u, 0000 


\section{FULL PAPERS}

Complex separation: Microbial production of 2,3-butanediol based on renewable resources enables high titers; however, the recovery of this hydrophilic high-boiling compound from aqueous fermentation broths remains challenging. Anionic extraction based on reversible esterification with phenylboronate is proposed for the isolation of 2,3-butanediol from aqueous solutions. The recovered bio-2,3-butanediol can be efficiently transformed into methyl ethyl ketone.

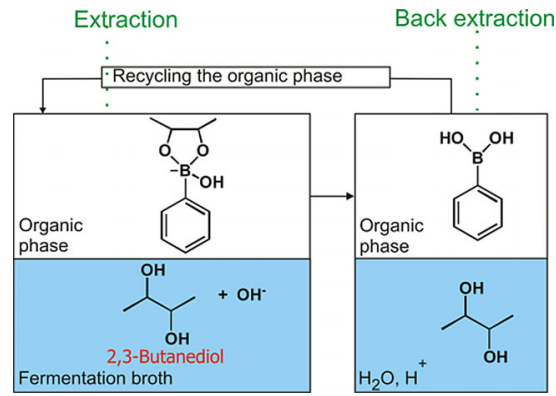

P. Drabo, T. Tiso, B. Heyman, E. Sarikaya, P. Gaspar, J. Förster, J. Büchs, L. M. Blank, I. Delidovich*

Anionic Extraction for Efficient Recovery of Biobased 2,3-Butanediol-A Platform for Bulk and Fine Chemicals 